University of Wollongong

Research Online

Faculty of Engineering - Papers (Archive)

Faculty of Engineering and Information

Sciences

30-4-2005

\title{
A shear strength model for idealised infilled joints under constant normal stiffness
}

Buddhima Indraratna

University of Wollongong, indra@uow.edu.au

S. Welideniya

University of Moratuwa, Sri Lanka

T. Brown

Golder Associates, Australia

Follow this and additional works at: https://ro.uow.edu.au/engpapers

Part of the Engineering Commons

https://ro.uow.edu.au/engpapers/386

\section{Recommended Citation}

Indraratna, Buddhima; Welideniya, S.; and Brown, T.: A shear strength model for idealised infilled joints under constant normal stiffness 2005.

https://ro.uow.edu.au/engpapers/386

Research Online is the open access institutional repository for the University of Wollongong. For further information contact the UOW Library: research-pubs@uow.edu.au 


\title{
A shear strength model for idealised infilled joints under constant normal stiffness
}

\author{
B. INDRARATNA*, H. S. WELIDENIYA $\dagger$ and E. T. BROWN:
}

\begin{abstract}
Infill materials found in natural rock joints may cause a reduction in joint shear strength, influencing rock mass stability. This paper reports a study aimed at developing a semi-empirical methodology for predicting the shear strength of infilled joints, taking into account joint surface characteristics and the properties of the joint and infill materials. A new model for predicting the shear strength of infilled joints is presented, on the basis of a series of tests carried out on two types of model joint surface having asperity angles of $9 \cdot 5^{\circ}$ and $18 \cdot 5^{\circ}$, with graphite and bentonite used as infill materials. All tests were carried out in a large-scale shear apparatus under constant normal stiffness (CNS) conditions. The results indicate that at low infill thickness to asperity height ratio $(t / a)$, the combined effect of the basic friction angle $\left(\phi_{\mathrm{b}}\right)$ and the joint asperity angle $(i)$ is pronounced, but it diminishes with increasing $t / a$ ratio so that the shear strength converges towards that of the infill alone. Summation of two algebraic functions $(A$ and $B)$ that represent the joint and infill characteristics correctly models the decay of normalised shear strength with increasing $t / a$ ratio. The new model successfully describes the observed shear strengths of the graphite and clay (bentonite) filled model joints.
\end{abstract}

KEYWORDS: deformation; friction; laboratory tests; shear strength; soft rocks; stiffness
Les matériaux de remplissage trouvés dans les joints rocheux naturels peuvent causer une diminution de la résistance au cisaillement du joint, influençant la stabilité de la masse rocheuse. Cet exposé rend compte d'une étude destinée à développer une méthodologie semiempirique pour prédire la résistance au cisaillement de joint remplis, prenant en compte les caractéristiques de surface du joint et les propriétés du joint et des matériaux de remplissage. Nous présentons un nouveau modèle pour prédire la résistance au cisaillement de joints remplis, en nous basant sur une série de tests effectués sur deux types de surfaces de joints modélisés ayant des angles d'aspérité de $9,5^{\circ}$ et $18,5^{\circ}$, du graphite et de la bentonite étant utilisés comme matériaux de remplissage. Tous les essais ont été effectués dans un appareil de cisaillement grandeur nature dans des conditions de rigidité normales constantes (CNS). Les résultats indiquent qu'avec un rapport bas entre l'épaisseur de remplissage et la hauteur d'aspérité $(t / a)$, l'effet combiné de l'angle de friction de base $\left(\phi_{\mathrm{b}}\right)$ et l'angle d'aspérité de joint (i) est prononcé mais il diminue à mesure que le rapport $t / a$ augmente si bien que la résistance au cisaillement converge vers celle du remplissage seul. La sommation de deux fonctions algébriques $(A$ et $B)$ qui représentent le joint et les caractéristiques de remplissage modélisent correctement la dégradation de la résistance au cisaillement normalisée en fonction de l'augmentation du rapport $t / a$. Le nouveau modèle décrit avec succès les résistances au cisaillement observées pour les joints modélisés remplis de graphite et d'argile (bentonite).

\section{INTRODUCTION}

Rock masses are typically characterised by joints, fractures and other planes of weakness that reduce their shear strengths and stiffnesses (e.g. Hoek, 1983; Brown, 2004). Rock masses often deform and fail on filled joints, because, as infill has low frictional properties (e.g. graphite, chlorite and serpentine), it often produces the weakest planes available for the initiation of sliding (Jaeger and Cook, 1979; Ladanyi \& Archambault, 1977; Brady \& Brown, 2004). On the other hand, over time, certain sediments may strengthen joints by bonding (e.g. calcite cementation), although these joints may be weakened again on subsequent joint movement.

In the past, direct shear tests have been conducted on infilled joints, but mainly under constant normal load (CNL) or zero normal stiffness conditions (e.g. Kanji, 1974; Lama, 1978; Barla et al., 1985; Bertacchi et al., 1986; Pereira, 1990; Phien-wej et al., 1990; de Toledo \& de Freitas, 1993). For non-planar discontinuities, shearing often results in dila-

Manuscript received 8 April 2004; revised manuscript accepted 16 November 2004.

Discussion on this paper closes on 3 October 2005, for further details see p. ii.

* Faculty of Engineering, University of Wollongong, Australia.

$\dagger$ Faculty of Engineering, University of Moratuwa, Sri Lanka.

\$ Golder Associates Pty Ltd, Brisbane, Australia. tion as one asperity overrides another. In confined environments, as in underground mining operations, if the surrounding rock mass is unable to deform sufficiently, then an inevitable increase in the normal stress will occur during shearing. In these cases, the CNL condition is unrealistic because the normal stress changes considerably and continuously during shear displacement. Goodman (1976) and de Toledo \& de Freitas (1993) pointed out that different direct shear results would be expected if the values of normal stiffness were changed. However, since the normal stiffness could also be expected to increase with shear in confined situations, CNL testing has been preferred until recently for reasons of practical convenience. Taking cognisance of realistic field conditions in underground excavations and rocksocketed piles, for example, a number of researchers have recognised the relevance of CNS testing (e.g. Ohnishi \& Dharmaratne, 1990; Skinas et al., 1990; Haberfield \& Johnston, 1994). However, it is only relatively recently that Indraratna et al. (1999) have reported the results of CNS tests on clay-filled joints. They concluded that the shear response of an infilled joint is a combined effect of the joint and infill properties, joint geometry, normal stiffness $\left(k_{\mathrm{n}}\right)$ and the initial normal stress $\left(\sigma_{\mathrm{n} 0}\right)$.

Rock joints may contain infill materials transported by water and/or in-situ weathering products (gouge). Joints filled with wet clayey materials often have very low shear 
resistances, which may result in sudden rock mass sliding. Indraratna \& Haque (2000) refer to such an occurrence in the Hawkesbury Sandstone at Kangaroo Valley, New South Wales, Australia. Infill found in tectonically active environments may include magmatic intrusions such as graphite (Chappell, 1975). Graphite veins can cause significant reductions in the overall shear strengths of rock masses because of their low frictional properties, as in the collapse of some mine openings in Sri Lanka (Indraratna \& Welideniya, 2003).

The salient aspects of tribology, including the characterisation of surface roughness, the adhesion theory of friction and lubrication, and the process of mechanical wear through attrition (Czichos, 1978; Hutchings, 1992; Ludema, 1996), provide relevant insight into infilled rock joint behaviour. Design of mechanical components incorporating wear life and frictional performance, as well as testing and simulation of lubricated surfaces, have been the subject of much experimental and theoretical investigation. In this study, the way in which the type of infill and its thickness influence the shearing resistance in relation to the basic friction angle $\left(\phi_{\mathrm{b}}\right)$ of idealised joint profiles is described.

In light of the limited amount of research that has been carried out using CNS testing of infilled joints, the authors have carried out a programme of laboratory tests with clay (commercial bentonite), natural graphite and clayey fine sand being used as infill materials. Because of space limitations, only the results for the bentonite and graphite infills will be presented here, with more emphasis being placed on the graphite infill. The data for the clayey sand infill are presented and discussed in detail by Welideniya (2004). Regularly toothed model joints were used in the experiments. Although idealised triangular asperities may not resemble the undulating joint profiles encountered in the field, they provide a simplified and reproducible basis for comparing the effects of different types of infill upon shearing, and for elucidating the effects of varying normal loads on joint deformation under CNS conditions.

The key objective of this study was the development of a robust mathematical model for representing the CNS shear strength of infilled joints, using measurable parameters such as the basic angle of friction $\left(\phi_{\mathrm{b}}\right)$, the internal friction angle of the fill $\left(\phi_{\text {fill }}\right)$ and the ratio of infill thickness to asperity height $(t / a)$. Earlier joint models such as those of Newland \& Alley (1957), Patton (1966), Barton \& Choubey (1977) and Ladanyi \& Archambault (1977) considered the shear strength of clean joints in the absence of any infill or gouge material. Barton (1974) discussed the importance of including infill material in shear strength models, and, more recently, Papaliangas et al. (1993) elucidated the relevance of the infill thickness in relation to the asperity height. These studies have similarities with research conducted on the effects of lubrication on frictional behaviour of surfaces (Ludema, 1996), even though the lubrication film thicknesses are very thin (often microns) compared with rock joint infills. In order to fully understand how the shear strength of an infilled joint can be assessed, it is important to study the role of infill properties and the effect of infill thickness for a given joint geometry.

\section{THEORETICAL BACKGROUND}

In a classic study, Patton (1966) described the shear strength $(\tau)$ of rough joints with regular asperities as

$$
\tau=\sigma_{\mathrm{n}} \tan \left(\phi_{\mathrm{b}}+i\right)
$$

where $\sigma_{\mathrm{n}}$ is the normal stress, $\phi_{\mathrm{b}}$ is the basic friction angle of the joint surface, and $i$ is the angle made by the asperity with the direction of shear force application, usually taken to be horizontal. Here, and elsewhere in this paper, all stresses are taken to be effective stresses, but the customary prime notation will not be used in the interests of simplicity of expression.

Rock joints found in nature are usually not planar, but have rough and undulating surfaces. Clearly, shearing of a rough, undulating surface has to overcome the total sliding resistance. Equation (1) holds true for low values of normal stress $\left(\sigma_{\mathrm{n}}\right)$ where dilation is not restricted. If the normal stress rises above a certain value at which dilation is inhibited, degradation of the asperities occurs, and shearing may then take place across the asperities. In this case, the shear strength criterion must be modified to account for a new dilation angle that will be less than the original asperity angle (i). Under constant normal stiffness (CNS) conditions, as dilation is constrained by the surrounding rock mass, there will be an inevitable increase in the applied normal stress. This is why the CNS condition is more appropriate for some practical applications than the conventional direct shear test in which shearing of joints is carried out under a constant normal load. Under CNS conditions, and neglecting any breakage of the asperities, the shear stress developed by a joint can be determined as a function of the current normal stress at a given horizontal displacement $\left(\sigma_{\mathrm{n} h}\right)$, the asperity angle (dilation angle) and the basic friction angle of the joint surface $\left(\phi_{\mathrm{b}}\right)$, as given by equation (1).

In underground mining, for example, the displacement of rough discontinuities in a confined environment can be expected to cause an increase in the normal stress, which may promote asperity degradation with further shearing. The dilation under such conditions is expected to be less than that associated with the initial asperity angle. This case has been discussed by Seidel \& Haberfield (1995) using energy considerations. They showed that equation (1) may be rewritten to give

$$
\tau_{(h, \mathrm{CNS})}=\left(\sigma_{\mathrm{n} 0}+\Delta \sigma_{\mathrm{n} h}\right)\left[\frac{\tan \left(\phi_{\mathrm{b}}\right)+\tan (i)}{1-\tan \left(\phi_{\mathrm{b}}\right) \tan \left(i_{h}\right)}\right]
$$

where $\tau_{(h, \mathrm{CNS})}$ is the joint shear stress at a horizontal displacement of $h, \sigma_{\mathrm{n} h}$ is the corresponding normal stress, $i$ is the initial asperity angle, $i_{h}$ is the tangent to the dilation curve at a horizontal displacement of $h$ under CNS conditions, and $\sigma_{\mathrm{n} 0}$ is the initial normal stress.

The shear strength of an infilled joint cannot be described by equation (2), as the properties and thickness of the infill can be expected to reduce the shear strength of the joint. Previous research carried out on infilled joints has clearly demonstrated a significant loss in shear strength with increasing t/a ratio (Phien-wej et al., 1990). Comparison of the shear strengths of clean joints and the drop in strength caused by the infill was the main focus of the earlier research carried out by Indraratna et al. (1999) using a Fourier analysis approach (equations (3)-(5)). In this approach, the normalised shear strength drop of infilled joints $\left(\Delta \tau_{\mathrm{p}}\right)$ was fitted to a hyperbolic decay curve, and the empirical parameters ( $p$ and $q$ ) were determined assuming that the strength drop is a hyperbolic function of the t/a ratio, as shown in equation (4). The shear strength of the infilled joint was represented as a combination of Fourier functions simulating the change in normal stress from the initial value of $\sigma_{\mathrm{n} 0}$ and a modification to equation (2) to represent dilation more accurately:

$$
\begin{aligned}
& \left(\tau_{\mathrm{p}}\right)_{\text {infilled }}=\left(\tau_{\mathrm{p}}\right)_{\text {clean }}-\Delta \tau_{\mathrm{p}} \\
& \Delta \tau_{\mathrm{p}}=\sigma_{\mathrm{n} 0} \frac{t / a}{p \times(t / a)+q}
\end{aligned}
$$




$$
\begin{aligned}
\left(\tau_{\mathrm{p}}\right)_{\text {infilled }}= & {\left[\sigma_{\mathrm{n} 0}+\frac{k_{\mathrm{n}}}{A_{\mathrm{j}}}\left(\frac{a_{0}}{2}+a_{1} \cos \frac{2 \pi h_{\tau \mathrm{p}}}{T}\right)\right] } \\
& \left(\frac{\tan \phi_{\mathrm{b}}+\tan i}{1-\tan \phi_{\mathrm{b}} \tan i_{\mathrm{hp}}}\right)-\sigma_{\mathrm{n} 0} \frac{t / a}{p \times(t / a)+q}
\end{aligned}
$$

In equation (5), $h_{\tau \mathrm{p}}$ and $i_{\mathrm{hp}}$ are the horizontal displacement and dilation angle corresponding to the peak shear stress respectively, $k_{\mathrm{n}}$ is the normal stiffness, $i$ is the initial asperity angle, $\sigma_{\mathrm{n} 0}$ is the initial normal stress, $\phi_{\mathrm{b}}$ is the basic friction angle, $A_{\mathrm{j}}$ is the joint surface area, $a_{0}$ and $a_{1}$ are Fourier coefficients, $T$ is the period of integration of the Fourier series, $t / a$ is the ratio of infill thickness to asperity height ratio, and $p$ and $q$ are hyperbolic constants. The Fourier coefficients $\left(a_{0}\right.$ and $\left.a_{1}\right), h_{\tau \mathrm{p}}$ and $T$ have the dimensions of length.

Although convenient for predicting the shear strength, the major disadvantage of this model was the need to evaluate in advance the hyperbolic constants for various $t / a$ ratios and asperity profiles. Moreover, these constants were found to be often sensitive to the type of infill material present, and the hyperbolic fit was not always accurate for some types of infill such as graphite (Indraratna \& Welideniya, 2003).

\section{DEVELOPMENT OF A NEW SHEAR STRENGTH MODEL}

As shown in Fig. 1, the propagation of the failure plane is expected to be influenced by the $t / a$ ratio. When $t / a$ is less than some critical value, a part of the failure surface may propagate across the asperities (Fig. 1(a)), but when the $t / a$ ratio is much greater than unity, the failure plane will remain within the infill itself (Fig. 1(b)). At low normal stresses, when dilation is only slightly restricted and the

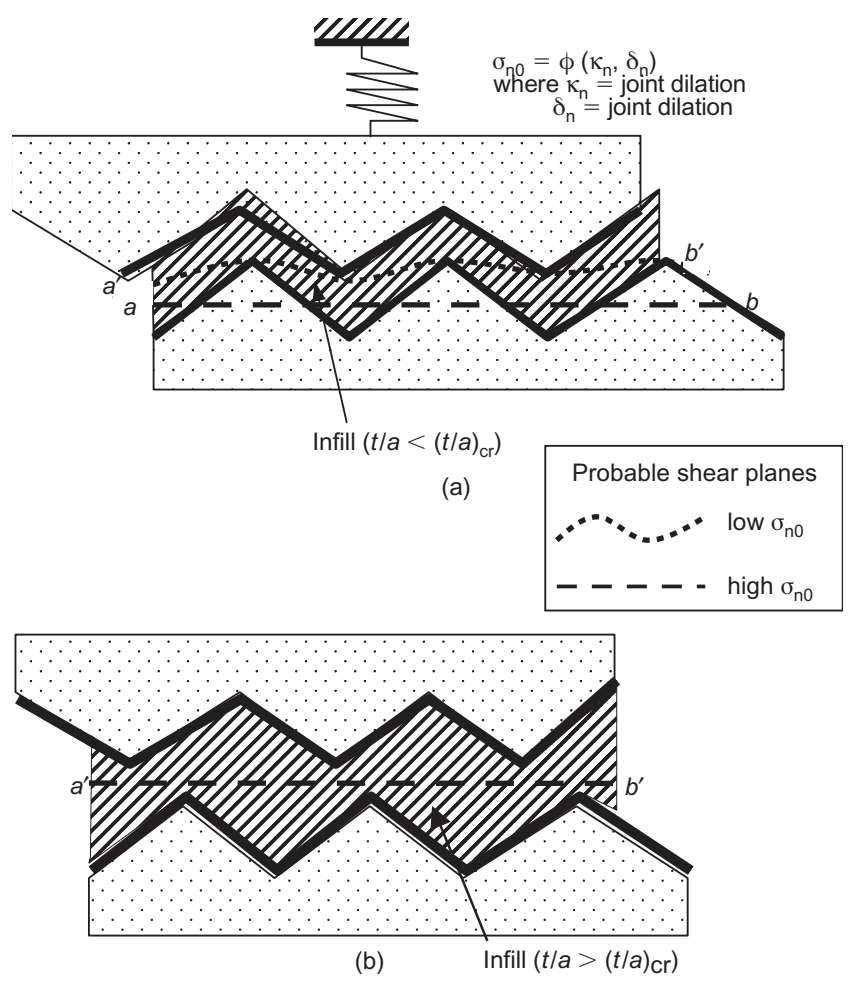

Fig. 1. Shearing modes of infilled joints: (a) interfering condition where $t / a<(t / a)_{\text {cr }}$ having two possible shear planes $a b$ and $a^{\prime} b^{\prime}$ depending on $\sigma_{\mathrm{n} 0}$; (b) non-interfering condition, i.e. $t / a>$ $(t / a)_{\text {cr }}$ where the potential shear plane through the fill is horizontal mobilised shear stress is not large enough to shear the asperities, the failure surface may follow a wavy pattern $\left(a^{\prime} b^{\prime}\right)$, as illustrated in Fig. 1(a). If the $t / a$ ratio is small, at high normal stresses, shearing occurs through asperities, and the failure surface will usually be horizontal $(a b)$. This is associated with suppressed dilation. In the case of small $t / a$ ratios, some breakage of asperities will be inevitable. In this situation, subsequent shearing will cause broken asperities to mix with the infill, changing the material's original shearing resistance.

The shear strength of infilled joints can be classified as falling into two major groups, on the basis of the t/a ratio. For joints in which the $t / a$ ratio is small, the 'interference' by the asperities is more pronounced than for joints having high $t / a$ ratios. In the latter case, the shear behaviour is often dictated by the infill. In this respect, the critical $t / a$ ratio is a function of the infill properties and the infill thickness, and is defined to separate the 'interfering' and 'non-interfering' zones as illustrated in Fig. 2. It is expected that different types of infill will give different critical $t / a$ ratios, which in general will exceed unity (Phien-wej et al., 1990; Indraratna et al., 1999). Moreover, for different types of joint, the critical $t / a$ ratio will change with the asperity angle $(i)$, as discussed below. As shown in Fig. 2, it is assumed that when the critical $t / a$ ratio is exceeded, the joint behaviour becomes a function of the shear strength of the infill alone.

\section{Normalised shear strength model}

Figure 2 shows the conceptual development of the shear strength model of infilled joints, based on two algebraic functions $A$ and $B$, the summation of which is assumed to give the normalised shear strength $\left(\tau_{\mathrm{s}} / \sigma_{\mathrm{n}}\right)$ for $t / a$ ratios of less than the critical value, $(t / a)_{\mathrm{cr}}$. For rough joints without infill, $t / a=0$, and the normalised shear strength is equal to $\tan \left(\phi_{\mathrm{b}}+i\right)$, as proposed by Patton (1966) for clean joints. As shown in Fig. 2, function $A$ is introduced to model the decrease in the influence of the $\tan \left(\phi_{\mathrm{b}}+i\right)$ term with increasing $t / a$ ratio, while function $B$ gradually increases the effect of the term $\tan \left(\phi_{\text {fill }}\right)$, until $(t / a)_{\text {cr }}$ is reached (the $\alpha$ and $\beta$ coefficients are greater than unity). At $(t / a)_{\mathrm{cr}}$, function $A$ becomes zero, and function $B$ becomes equal to $\tan \left(\phi_{\text {fill }}\right)$.

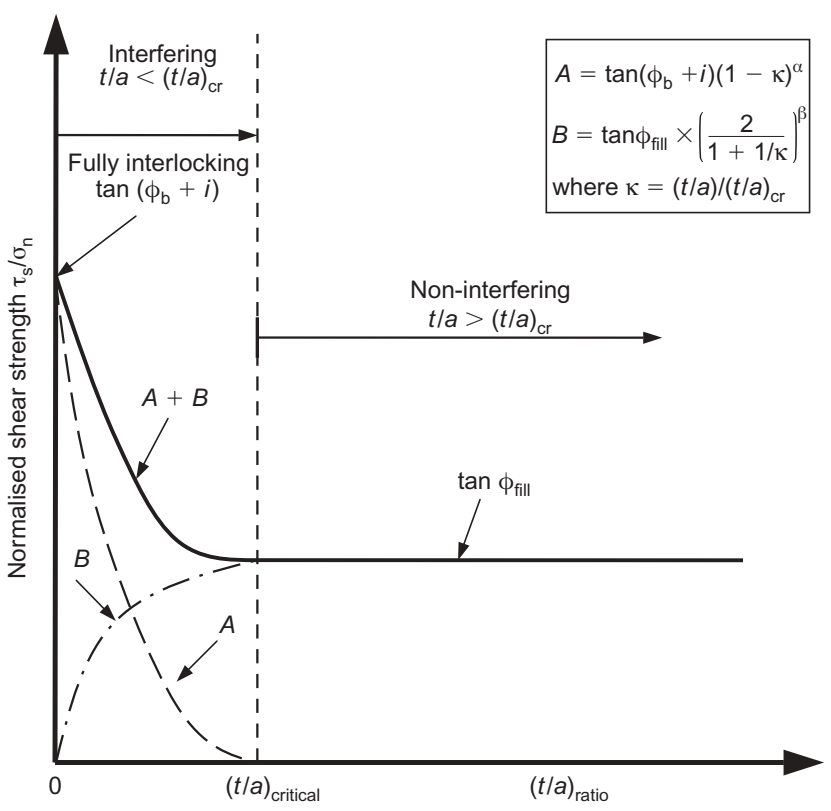

Fig. 2. Shear strength model for infilled joints showing the role of $\phi_{\mathrm{b}}$ and $\phi_{\text {fill }}$ 
Hence, for $t / a<(t / a)_{\mathrm{cr}}$ in the region of asperity 'interference':

$$
\begin{aligned}
A= & \tan \left(\phi_{\mathrm{b}}+i\right) \times(1-\kappa)^{\alpha} \\
B= & \tan \phi_{\mathrm{fill}} \times\left(\frac{2}{1+1 / \kappa}\right)^{\beta} \\
\frac{\tau_{\mathrm{s}}}{\sigma_{\mathrm{n}}}= & A+B=\tan \left(\phi_{\mathrm{b}}+i\right) \times(1-\kappa)^{\alpha}+\tan \phi_{\mathrm{fill}} \\
& \times\left(\frac{2}{1+1 / \kappa}\right)^{\beta}
\end{aligned}
$$

where $\kappa=(t / a) /(t / a)_{\mathrm{cr}}, \sigma_{\mathrm{n}}$ is the normal stress, $\phi_{\text {fill }}$ is the peak friction angle of infill, and $\alpha$ and $\beta$ are empirical constants defining the geometric locus of the functions $A$ and $B$.

For $t / a>(t / a)_{\mathrm{cr}}$, in the zone of 'non-interference' the normalised shear strength is given by the constant value

$$
\frac{\tau_{\mathrm{s}}}{\sigma_{\mathrm{n}}}=\tan \phi_{\text {fill }}
$$

In both equations (8) and (9), any cohesion $\left(c_{j}\right)$ of the joints has been ignored. The cohesion of a natural joint may have to be considered, for example, if there is joint cementation or there is a clayey infill, particularly when wet. Under such circumstances, the term $c_{\mathrm{j}} / \sigma_{\mathrm{n}}$ must be added to both equations (8) and (9). Graphite is a finely textured silt-like material that has no cohesion intercept (Welideniya, 2004). Haque (1999) demonstrated that commercial bentonite having a moisture content of $15 \%$ and sheared at a slow rate (fully drained) also shows a zero cohesion intercept in its CNS shear strength envelope. Therefore, within the scope of this study, any effect of cohesion in drained shearing will be neglected, and only the effect of infill friction will be considered. It is expected that, at increased infill thicknesses, the overall friction angle will be not only a function of the basic friction angle, $\phi_{\mathrm{b}}$, but also a function of the peak friction angle of the infill. The algebraic summation of $A$ and $B$ is assumed to represent the overall shear strength in the region $t / a<(t / a)_{\mathrm{cr}}$, where $\alpha$ and $\beta$ are empirical coefficients that must be determined from the test data for a given infill and joint geometry combination.

The parameter $(t / a)_{\mathrm{cr}}$ is defined as the critical value of $t / a$ at which the effects of the basic friction angle $\left(\phi_{\mathrm{b}}\right)$ and the asperity angle $(i)$ become negligible. The overall shear strength becomes governed by the term $\tan \left(\phi_{\text {fill }}\right)$ alone, as the effect of asperity geometry is suppressed by the relatively thick infill cover ('non-interfering' region) and the shear plane confined within the clay seam. Such behaviour has been observed by Nieto (1974) and de Toledo \& de Freitas (1993). As the $t / a$ ratio becomes even greater, and at much larger shear displacements, the shear strength may approach an ultimate (residual) value. In the University of Wollongong CNS apparatus where the maximum attainable shear displacement is small (less than $40 \mathrm{~mm}$ ), the mobilised value of $\phi_{\text {fill }}$ will still be close to its peak value. In the field where large shear displacements exceeding $100 \mathrm{~mm}$ can occur (Lupini et al., 1981), a realistic value for $\phi_{\text {fill }}$ should be the post-peak mobilised angle of shear resistance. The mathematical formulation presented in equations (6)-(9) may be modified to include strain dependence by varying the mobilised $\phi_{\text {fill }}$ between its peak and ultimate values if the shear strain is known and the ultimate value of $\phi_{\text {fill }}$ can be determined.

\section{EXPERIMENTAL PROCEDURES \\ Specimen preparation}

High-strength gypsum plaster $\left(\mathrm{CaSO}_{4} \cdot \mathrm{H}_{2} \mathrm{O}\right.$ hemihydrate, $98 \%$ ) was used to model the joints. The workability and favourable similitude properties of gypsum plaster make it a suitable material for modelling rock joints (Indraratna, 1990; Haque, 1999). Gypsum plaster mixed with water in a 5:3 ratio by weight forms a viscous paste that may be moulded readily into any shape. This paste was poured into $250 \times 75$ $\times 150 \mathrm{~mm}^{3}$ and $250 \times 75 \times 100 \mathrm{~mm}^{3}$ rectangular moulds having idealised joint surface profiles such as those shown in Fig. 1 with asperity angles of $9.5^{\circ}$ and $18.5^{\circ}$, referred to as Types 1 and 2 respectively. These two asperity angles correspond to asperity heights $(a)$ of $2.5 \mathrm{~mm}$ and $5 \mathrm{~mm}$ respectively (Table 1 ).

During specimen preparation, a mild vibration was applied to the sides of the moulds to release any entrapped air. At the end of an initial setting time of $30 \mathrm{~min}$, the specimens were removed from the casting box and cured at an ovencontrolled temperature of $45^{\circ} \mathrm{C}$ for two weeks. On removal from the oven, they were allowed to cool down to room temperature. For cylindrical specimens with a height/diameter ratio of 2 , the unconfined compressive strength $\left(\sigma_{\mathrm{c}}\right)$ was consistently measured as $13-15 \mathrm{MPa}$, and the elastic modulus $(E)$ as $1.9-2.3 \mathrm{GPa}$ at $50 \%$ of peak stress. The mean $E / \sigma_{\mathrm{c}}$ ratio in the order of 150 is typical of most sedimentary rocks (Indraratna, 1990).

Indraratna et al. (1999) have described in detail the procedure used for casting infilled joints, so only a summary will be given here. An adjustable collar having the desired surface profile was attached to the top of the cured lower half of the specimen in such a way that the surface profile projected above the bottom specimen, thereby creating an enclosure over the specimen in which to cast the predetermined height of infill. In this paper, the CNS shear behaviour of commercial bentonite clay and natural graphite powder blended with $5 \%$ gypsum as infill materials is discussed. The addition of a small amount of gypsum to the graphite powder produced a workable infill that provided sufficient bonding with the plaster (joint) surface. The moistened mix (at an initial water content of 20\%) was spread over the surface at the predetermined height, and then compacted and trimmed with a spatula as necessary. In this manner, the infill thickness was varied from 3 to $9 \mathrm{~mm}$ for both Type $1\left(i=9 \cdot 5^{\circ}\right)$ and Type $2\left(i=18 \cdot 5^{\circ}\right)$ joints. Speci-

Table 1. Empirical constants of the proposed shear strength model

\begin{tabular}{l|l|c|c|c}
\hline Joint type & Type of infill & $(t / a)_{\text {cr }}$ & $\alpha$ & $\beta$ \\
\hline Type 1 & Graphite $\left(\phi_{\text {fill }}=21^{\circ}\right)$ & $1 \cdot 2$ & $1 \cdot 7$ & $1 \cdot 3$ \\
$i=9 \cdot 5^{\circ}$ & Bentonite $\left(\phi_{\text {fill }}=25^{\circ}\right)$ & $1 \cdot 5$ & $1 \cdot 2$ & $1 \cdot 4$ \\
$a=2 \cdot 5 \mathrm{~mm}$ & Clayey sand $\left(\phi_{\text {fill }}=30^{\circ}\right)$ & $1 \cdot 4$ & $1 \cdot 1$ & $2 \cdot 5$ \\
Type 2 & Graphite $\left(\phi_{\text {fill }}=21^{\circ}\right)$ & $1 \cdot 4$ & $1 \cdot 5$ & $2 \cdot 2$ \\
$i=18 \cdot 5^{\circ}$ & Bentonite $\left(\phi_{\text {fill }}=25^{\circ}\right)$ & $1 \cdot 8$ & $1 \cdot 1$ & $3 \cdot 1$ \\
$a=5 \mathrm{~mm}$ & Clayey sand $\left(\phi_{\text {fill }}=30^{\circ}\right)$ & $1 \cdot 6$ & $1 \cdot 1$ & $4 \cdot 4$ \\
\hline
\end{tabular}

Note: $\frac{\tau_{\mathrm{s}}}{\sigma_{\mathrm{n}}}=A=B=\tan \left(\phi_{\mathrm{b}}+i\right) \times(1-\kappa)^{\alpha}+\tan \phi_{\text {fill }} \times\left(\frac{2}{1+1 / \kappa}\right)^{\beta}$ 
mens containing infill were cured for $24-48 \mathrm{~h}$ at room temperature, until the water content of infill was reduced below $20 \%$.

After having placed the infill and dismantled the collar, the bottom specimen was placed within the shear apparatus and fixed firmly by tightening all the screws. The top shear box (containing the upper half of the specimen) was then placed over the bottom specimen in a fully mated position and, simultaneously, the lateral support plates were assembled around the infill joint to prevent loss of infill during the shearing process. All joints were initially consolidated and then sheared under a predetermined initial normal stress, $\sigma_{\mathrm{n} 0}=0.30,0.56,1 \cdot 10$ or $2.43 \mathrm{MPa}$. Fig. 1 illustrates the relative movement of the infilled joint on shearing. For graphite-infilled joints, the maximum compression under $\sigma_{\mathrm{n} 0}=2.43 \mathrm{MPa}$ corresponded to a post-consolidation void ratio in the vicinity of $0 \cdot 35$. For the same load, the postconsolidation void ratios for bentonite and clayey sand were in the order of 0.75 and 0.55 respectively.

\section{Testing procedure}

In the CNS apparatus, the upper box can move vertically and the lower box can only move horizontally. The normal and shear load capacities of the CNS apparatus are $180 \mathrm{kN}$ and $120 \mathrm{kN}$ respectively. The normal load was applied by a set of four springs having an overall normal stiffness $k_{\mathrm{n}}$ of $8.5 \mathrm{kN} / \mathrm{mm}(=0.45 \mathrm{GPa} / \mathrm{m}$ for a joint area of $190 \mathrm{~mm} \times$ $100 \mathrm{~mm}$ ). Although this value is less than that of many natural rock joints, it is representative of weathered sandstone (Kangaroo Valley, Australia), graphite veins in sedimentary formations and some coal measures rock masses, representing jointed and interbedded sandstone, shale and mudstone (Haque, 1999; Indraratna et al., 1999). Moreover, as the parent rock is modelled by gypsum plaster (equivalent to very soft rock), a relatively low value of $k_{\mathrm{n}}$ is appropriate. The overall stiffness of the CNS apparatus loading through the spring assembly enables the complete stress-strain behaviour of the test specimens (Figs 3 and 4), to be followed without any uncontrolled brittle instability (Brady \& Brown,
2004). However, testing of much stiffer rock joints may require the use of a much stiffer spring assembly and test frame.

Infilled joints were subjected to predetermined initial normal stress $\left(\sigma_{\mathrm{n} 0}\right)$ for $45-60 \mathrm{~min}$ before shearing. The values of $\sigma_{\mathrm{n} 0}$ of $0.56,1.1$ and $2.43 \mathrm{MPa}$ were selected as being representative of the underground graphite mines at Bogala, Sri Lanka (Welideniya, 2004). Each test consisted of two stages of shearing: the forward (first cycle) and reverse shearing (second cycle) stages. All model joints were sheared at a constant slow shearing speed of $0.5 \mathrm{~mm} / \mathrm{min}$ to ensure fully drained shearing (de Toledo \& de Freitas, 1993; Haque, 1999). The reverse shearing stage may involve remoulded infill mixed with some broken asperities from the first cycle. Also, the reverse shearing may represent the post-peak shear behaviour of infilled joints, but the residual shear strength is impossible to achieve in the CNS shear apparatus given the limited horizontal (shearing) displacement of $40 \mathrm{~mm}$ available. It may be necessary to shear for a distance exceeding $100 \mathrm{~mm}$ for soils (Lupini et al., 1981) and at least $200 \mathrm{~mm}$ for clean rock joints (Kutter \& Rautenberg, 1979; Xu \& de Freitas, 1988) to reach the residual shear strength. Tests were repeated to ensure consistency and reliability, giving a total of 120 tests for each infill under CNS conditions. Only selected test results are presented and discussed here.

\section{EXPERIMENTAL RESULTS}

Figures 3 and 4 show the shear stress against horizontal displacement plots for selected Type $1\left(i=9 \cdot 5^{\circ}\right)$ and Type 2 $\left(i=18 \cdot 5^{\circ}\right)$ specimens having graphite-infilled joints. Shear stresses have been calculated using the corrected crosssectional area of the specimen at each displacement. Results are plotted for two different $t / a$ ratios corresponding to infill thickness of $3 \mathrm{~mm}$ and $9 \mathrm{~mm}$, and for three levels of the initial normal stress. Both forward and reverse shearing cycles are plotted, up to a maximum horizontal displacement of $40 \mathrm{~mm}$ in one direction. The plots of shear stress against horizontal displacement for bentonite-infilled joints have

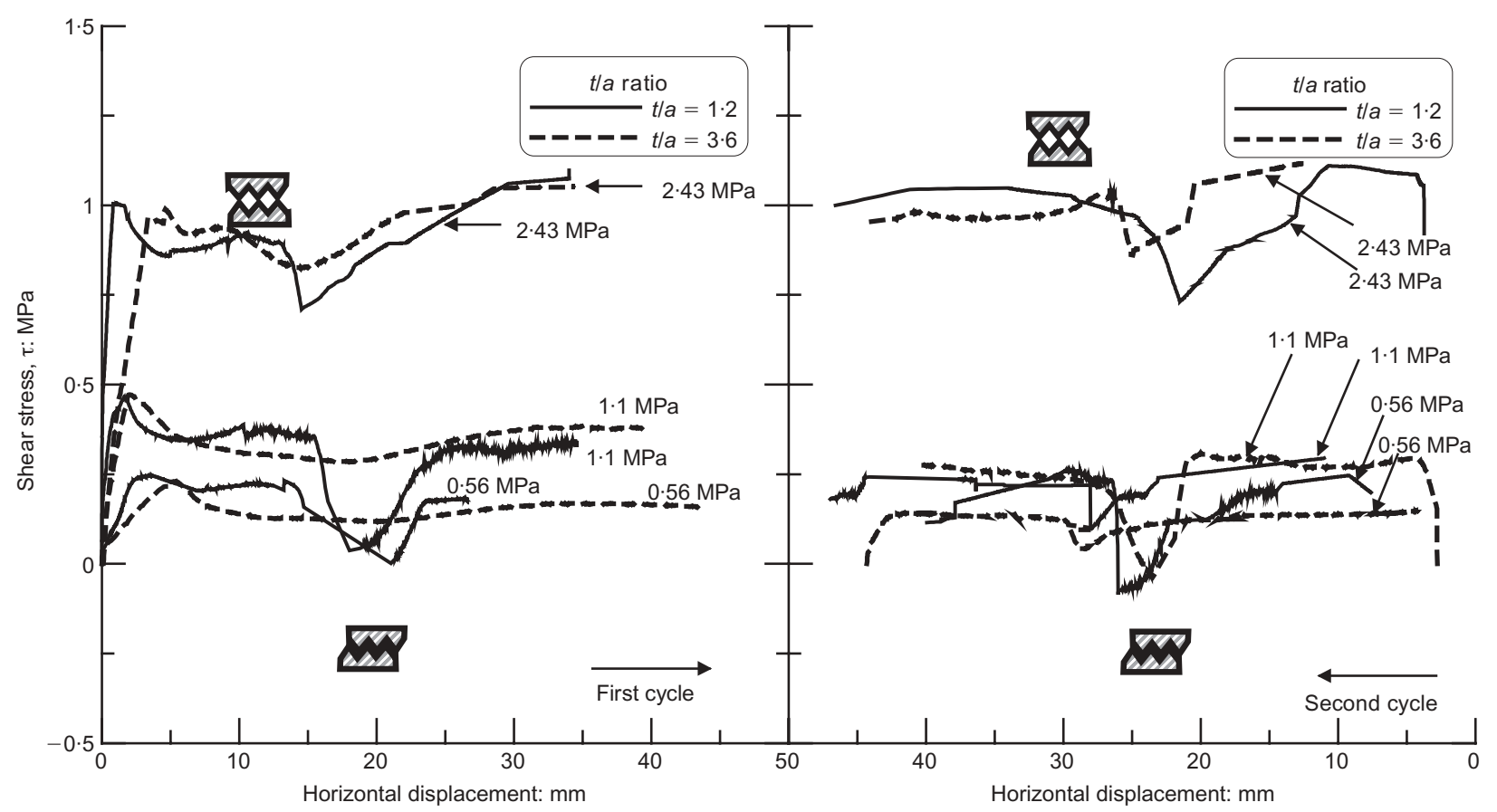

Fig. 3. Shear response of Type 1 joint with $3 \mathrm{~mm}$ and $9 \mathrm{~mm}$ graphite infill $(t / a=1.2$ and 3.6 respectively) for first and second cycles of shearing at different initial normal stresses 


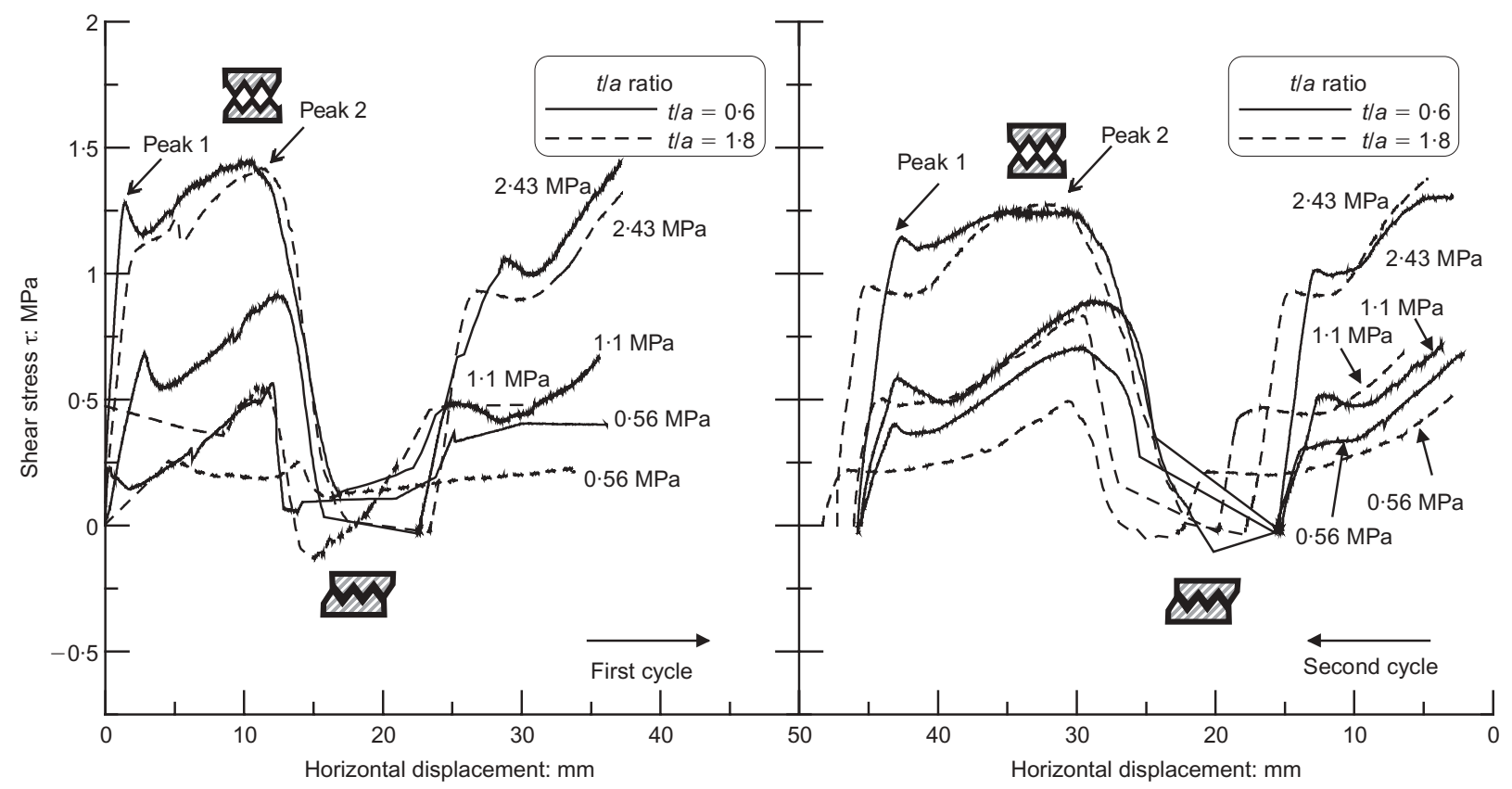

Fig. 4. Shear response of Type 2 joint with $3 \mathrm{~mm}$ and $9 \mathrm{~mm}$ graphite infill (t/a=0.6 and 1.8 respectively) for first and second cycles of shearing at different initial normal stresses

been discussed by Indraratna et al. (1999) and will not be presented here.

\section{Shear behaviour of Type 1 joints $\left(i=9.5^{\circ}\right)$}

Figure 3 shows the plots of shear stress against horizontal displacement for six selected joint specimens having two values of infill thickness ( $3 \mathrm{~mm}$ and $9 \mathrm{~mm}$ ) corresponding to $t / a$ ratios of 1.2 and $3 \cdot 6$. The initial normal stresses are indicated on the plots. Because $t / a>1$ for all Type 1 specimens, the shear behaviour was expected to be governed largely by the infill. Clearly, the shear stress plots of the three specimens having $t / a=3 \cdot 6$ (the dashed lines in Fig. 3) show a 'ductile' response, with an initial peak being reached after a small displacement. This is in accordance with the stress-strain behaviour of compacted graphite (Welideniya, 2004). However, for $t / a=1 \cdot 2$, the rapidly attained peak at small strain is then followed by a strength drop and a second peak at a shear displacement of about $8-10 \mathrm{~mm}$. While the first peak represents mainly infill deformation with some increased asperity interference (compared with the $t / a=3.6$ case), the development of the second peak reflects the effect of the joint surface shearing over asperities towards the 'peak-to-peak' position. Subsequently, the shear stress drops to a minimum at the 'fully mated' position after a displacement of about $15-20 \mathrm{~mm}$. The next peak occurs when the overriding of the asperities reoccurs, as evident from the first cycle of shearing. The cyclic nature of the shear stress change is much less noticeable for $t / a=3 \cdot 6$, except at the highest value of $\sigma_{\mathrm{n} 0}$ of $2.43 \mathrm{MPa}$. These observations confirm that, with significantly increased infill thickness $(t / a>1)$, the shear behaviour is governed mainly by infill alone, and that the influence of the joint asperities is more pronounced at higher normal stresses. Reverse shearing (the second cycle) produces a similar plot. The asperity 'peak-topeak' and 'fully mated' positions are associated with the maxima and minima of the shear stress plots.

The changes recorded in the normal stress and dilation with horizontal displacement can be summarised in the following way. When the $t / a$ ratio was increased, a reduction in the shear stress at any given horizontal displacement was accompanied by reductions in normal stress and dilation. At the higher infill thickness of $9 \mathrm{~mm}(t / a=3 \cdot 6)$, dilation during shearing was insignificant, as the shear plane propagated within the clay seam with minimum asperity interference (see Fig. 1(b)). At the maximum initial normal stress, $\sigma_{\mathrm{n} 0}=2.43 \mathrm{MPa}$, an overall compression of up to $0.2 \mathrm{~mm}$ was recorded at a horizontal displacement approaching $10 \mathrm{~mm}$. For joints with $t / a=1 \cdot 2$, initial infill compression was followed by a slight dilation of up to $1 \mathrm{~mm}$ during subsequent shearing. For all Type 1 joints, the increase in normal stress $\left(\sigma_{\mathrm{n}}\right)$ was usually associated with an increase in shear stress and a reduction in joint dilation.

\section{Shear behaviour of Type 2 joints $\left(i=18 \cdot 5^{\circ}\right)$}

Figure 4 shows the shear response of Type 2 joints for graphite infill thicknesses of $3 \mathrm{~mm}$ and $9 \mathrm{~mm}$ corresponding to $t / a$ ratios of 0.6 and 1.8 respectively. For $t / a=0.6$, the shear stress begins with a rapid rise to 'peak 1', associated with infill dilation, which becomes less significant with continued shearing. The subsequent stress-displacement response reflects asperity 'interference' over the infill, and the more pronounced 'peak 2' is the result of 'peak-to-peak' position. A rapid reduction in shear stress then follows when the joint slides to the 'fully mated' position. The subsequent increase in shear stress is almost symmetrical as asperity overriding occurs again. The twin-peak phenomenon for infilled joints was also observed by de Toledo \& de Freitas (1993) in conventional (CNL) direct shear testing. Comparison of the results for the two joint types shows that when $t /$ $a>1$, the existence of two peaks is not as pronounced in Type 1 joints as in Type 2 . Therefore the $t / a$ ratio alone does not provide a complete comparison of joint behaviour. The joint boundary or asperity angle $(i)$ must also be considered. However, beyond the critical $t / a$ ratio, the shear behaviour is independent of the joint boundaries.

For $\sigma_{\mathrm{n} 0}=2.43 \mathrm{MPa}$, the reverse shearing stage (the second cycle) shows about a 10\% reduction in peak shear stress. This is attributed to asperity degradation under high normal stress, as observations of some joints after the initial cycle of shearing clearly showed evidence of broken aspe- 
rities and 'blended' gouge. Observations of tested samples indicated that orientation of infill in the direction of shearing was more obvious for the higher $t / a$ ratios. Even at low $t / a$ ratios, graphite infill compacts to form 'fine layering' even when remoulded with broken asperities. In practice, large horizontal displacements may bring the friction angle of the infill towards its post-peak ultimate (residual) value, thereby decreasing the shear strength of the infilled joints considerably (Kutter \& Rautenberg, 1979). This reduction in postpeak strength is expected to be greater for graphite than for a clay infill. Using large shear displacement tests, Welideniya (2004) has shown that the ultimate value of $\phi_{\text {fill }}$ for graphite plunges to about $10^{\circ}$ when overly compacted and sheared (polished surface), whereas for bentonite the drop from peak to ultimate is more gradual. On the other hand, it may be argued that mixing broken asperities with graphite infill may cause some increase in the apparent shear strength of the blended gouge, giving an ultimate angle of friction $\left(\phi_{\text {ult }}\right)$ greater than that of the infill alone.

\section{Variation of normal stress and dilation}

The changes in normal stress and dilation with horizontal displacement for Type 1 and Type 2 joints have been described in detail by Welideniya (2004). It is noted that, in a CNS test, normal stress and dilation changes are linearly related and have similar trends. At the same shear displacement, Type 2 joints $(t / a=0.6$ and 1.8$)$ show greater increases in normal stress than Type 1 joints $(t / a=1 \cdot 2$ and 3.6). As expected, the maximum increases in normal stress and dilation were observed for Type 2 joints with $t / a=0 \cdot 6$. During shearing, the maximum normal stress and dilation are attained when the asperities are in a 'peak-to-peak' contact, and a subsequent drop to their minima coincides with the minimum shear stress, when the joint surfaces are in the 'fully mated' position.

At lower values of $\sigma_{\mathrm{n} 0}$ the infill thickness plays a greater role, whereas with increasing $\sigma_{\mathrm{n} 0}$ the role of the asperities becomes more pronounced, even if the infill thickness is increased. Irrespective of the infill thickness, the data show that, when the joints attain the maximum normal stress, the corresponding shear stress is also close to a maximum, and vice versa. However, the extent of dilation/compression depends on the infill thickness ( $t / a$ ratio) and the level of the initial normal stress, $\sigma_{\mathrm{n} 0}$. In the reverse shearing cycle, the same trend as in the first cycle continues, except that a slightly increased normal stress and dilation are observed. This is due to the accumulation of strain-hardened infill transferred from the loaded to the unloaded zones during the first (forward) cycle now being reversed, so that, at the start of the second (reverse) cycle, the asperities will need to override the accumulated gouge, reducing the overall dilative effect.

\section{General effects of the t/a ratio and the initial normal stress} $\left(\sigma_{\mathrm{n} 0}\right)$

Asperity interference is usually significant at all levels of normal stress, but at high infill thickness $(t / a>1)$, the effect of asperity interference is generally reduced. At higher initial normal stresses $\left(\sigma_{\mathrm{n} 0}>2.43 \mathrm{MPa}\right)$, the strength of asperity material may become comparable to infill. At low fill thickness ( $t / a$ of around 1.0 or less), the potential shear (failure) plane tends to intersect the rock asperities; but if the normal stress is small, the maximum shear stress may not be large enough to shear the asperities, and the joint will dilate during asperity overriding. At higher $\sigma_{\mathrm{n} 0}$ values, the corresponding shear stress may break the asperities, resulting in a horizontal shear plane on which minimum dilation occurs.
In the subsequent cycles of shearing, it is anticipated that asperity degradation (breakage and smoothing) and continued straining of the infill may produce reduced peaks (compared with the first cycle), fewer irregularities and increased 'ductility' of the shear stress plots.

During the progress of shearing, the infill material above the failure plane from the stressed side will be squeezed into the void created in the unloaded side of the joint, causing a further increase in joint shear strength (de Toledo \& de Freitas, 1993). In the present study it was also observed that, as soon as the 'peak-to-peak' contact position is approached, it becomes harder to squeeze the strain-hardened infill into the unloaded zone, producing an apparent sharp rise in the pre-peak shear stress (see Fig. 4).

\section{Experimental verification of the normalised shear strength model}

The results of the 240 shear tests (including repeats) conducted on Types 1 and 2 graphite- and bentonite-filled joints were used to validate the new shear strength model. Additional test data were also available for bentonite infill from previous tests (Haque, 1999). In this case, the infill thickness was varied from 1.5 to $9 \mathrm{~mm}$ corresponding to $\mathrm{t} / \mathrm{a}$ ratios of $0 \cdot 3-3 \cdot 6$.

The peak shear stress of infilled joints gradually rises with increasing $\sigma_{\mathrm{n} 0}$ and asperity angle, as shown in Fig. 5 for graphite-filled joints. These peaks are taken as the maximum values measured during shearing averaged over a few identical tests. The proposed shear strength criterion for infilled joints is a relation between the peak shear stress normalised by the corresponding normal stress $\left(\tau_{\mathrm{s}} / \sigma_{\mathrm{n}}\right)$ and the corresponding $t / a$ ratio. Figs 6 and 7 show the variation of $\tau_{\mathrm{s}} / \sigma_{\mathrm{n}}$ with $t / a$ ratio for graphite and bentonite infills respectively. Irrespective of $\sigma_{\mathrm{n} 0}$, after normalisation, all the laboratory data fall within a narrow band (compare with Fig. 5). When the $t / a$ ratio is increased, $\tau_{\mathrm{s}} / \sigma_{\mathrm{n}}$ decreases rapidly, but beyond $(t / a)_{\text {cr }}$ the decline in $\tau_{\mathrm{s}} / \sigma_{\mathrm{n}}$ is marginal. This verifies that, beyond $(t / a)_{\mathrm{cr}}$, the shear strength is predominantly a function of the infill properties. Beyond $(t / a)_{\mathrm{cr}}$ the normalised shear strength ratio $\left(\tau_{\mathrm{s}} / \sigma_{\mathrm{n}}\right)$ approaches the value of $\tan \phi_{\text {fill }}$.

It is noted that the ultimate value of $\tau_{\mathrm{s}} / \sigma_{\mathrm{n}}$ (when $t / a>$ $\left.(t / a)_{\mathrm{cr}}\right)$ for graphite-infilled joints is slightly less than that for the bentonite-infilled joints. In Fig. 6, for Type 1 joints, some laboratory data plot very close to or below the $\phi_{\text {fill }}=$ $21^{\circ}$ reference line. Some previous tests conducted by the authors on plane joints $\left(i=0^{\circ}\right)$ with graphite infill indicated the same trend. This is because, as noted earlier, joints with $t / a>(t / a)_{\mathrm{cr}}$ sheared under high $\sigma_{\mathrm{n} 0}$, produce a compacted (layered) and oriented (polished) shear plane giving a reduced angle of friction (see Fig. 8). At elevated normal stress levels for Type 1 joints $\left(\sigma_{\mathrm{n} 0}=2.43 \mathrm{MPa}\right)$, the apparent friction angle of the joint decreases by up to $20 \%$ at a shear strain exceeding $4-5 \%$. However, when the asperity angle is greater (Type 2 joints with $i=18.5^{\circ}$ ) and at low $t / a$ ratios, this decline in the friction angle is observed only at the higher values of $\sigma_{\mathrm{n} 0}$ (see Fig. 6(b)). In contrast, for bentonite infill, irrespective of the shear stresses permissible in the CNS apparatus, the apparent friction angle remains relatively unchanged at around $25^{\circ}$, as shown in Fig. 7. This observation highlights the unfavourable properties of graphite. A significant reduction in post-peak shear strength at relatively small shear strains has obvious implications for stability in graphite mines.

The decrease in $\tau_{\mathrm{s}} / \sigma_{\mathrm{n}}$ with increasing $t / a$ is in agreement with the mathematical 'decay function' introduced in equations (6)-(9). As noted earlier, the algebraic expression $A$ represents the decay of the maximum joint friction, while the term $B$ models the increasing role of the infill angle of 


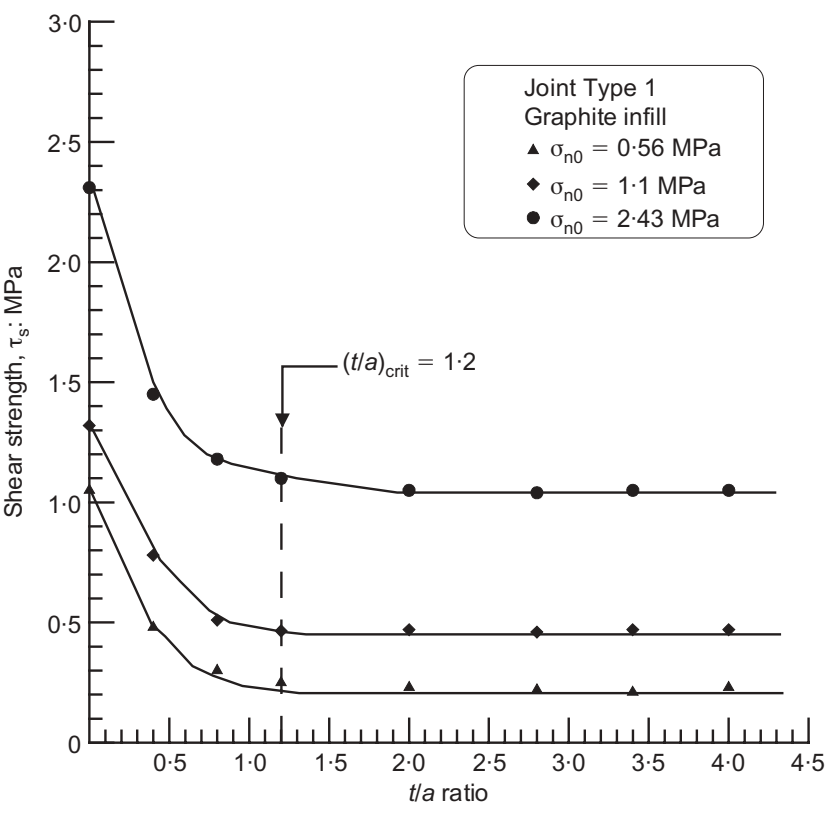

(a)

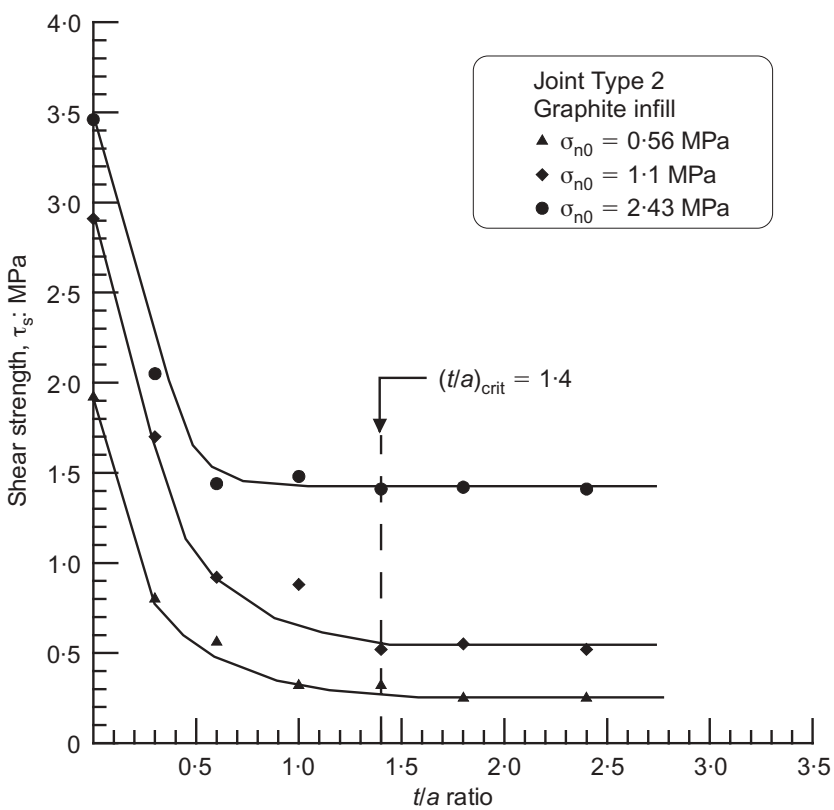

(b)

Fig. 5. Variation of shear strength of graphite-infilled joints with $t / a$ ratio: (a) Type 1 joint; (b) Type 2 joint

friction. The normalised shear strength for $t / a<(t / a)_{\mathrm{cr}}$ is then given by equation (8). For $t / a>(t / a)_{\mathrm{cr}}$ the mathematical model assumes the normalised shear strength to be unchanged, as given by equation (9).

As shown by Fig. 9, the laboratory data for graphite and bentonite infill verify the model very well for both Type 1 and Type 2 joints. The empirical parameters $\alpha$ and $\beta$ were determined by multi-regression, and are tabulated in Table 1 for three infill types together with the respective critical $t / a$ ratios. Fig. 9 shows that, with increased asperity angle, the critical ratio $(t / a)_{\text {cr }}$ increases for the same infill type. For Type 2 joints, $(t / a)_{\mathrm{cr}}$ is slightly greater than for Type 1 joints. It appears that $(t / a)_{\text {cr }}$ has no distinct relation with the value of $\phi_{\text {fill }}$ for the three types of infill used (Table 1). The magnitudes of $\alpha$ and $\beta$ are characteristic of a given joint geometry-infill combination under CNS conditions. In Table 1 they correspond to texturally different infill materials: (a)

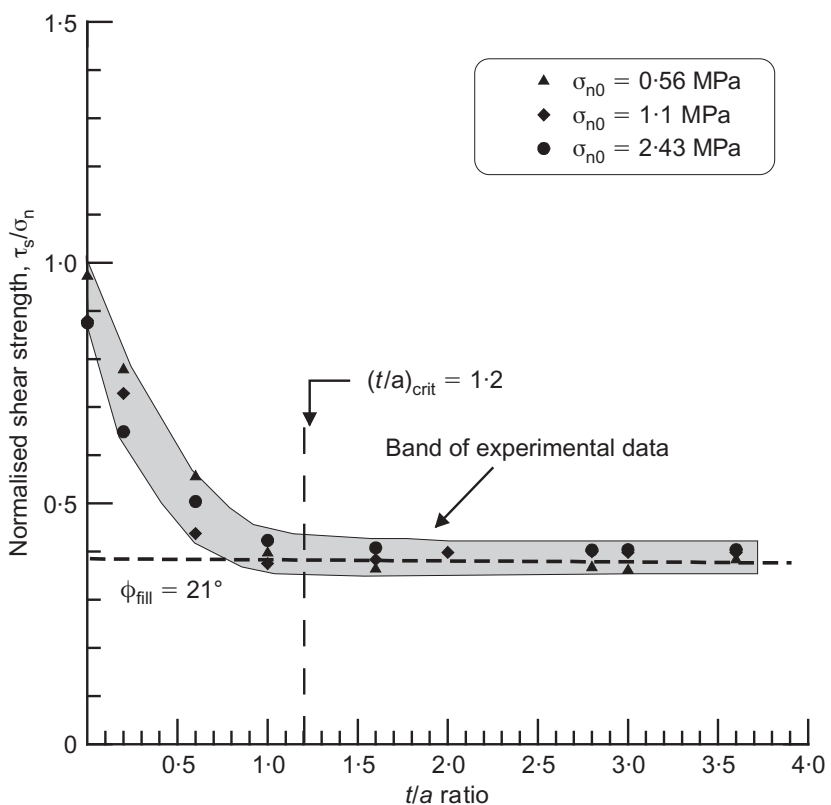

(a)

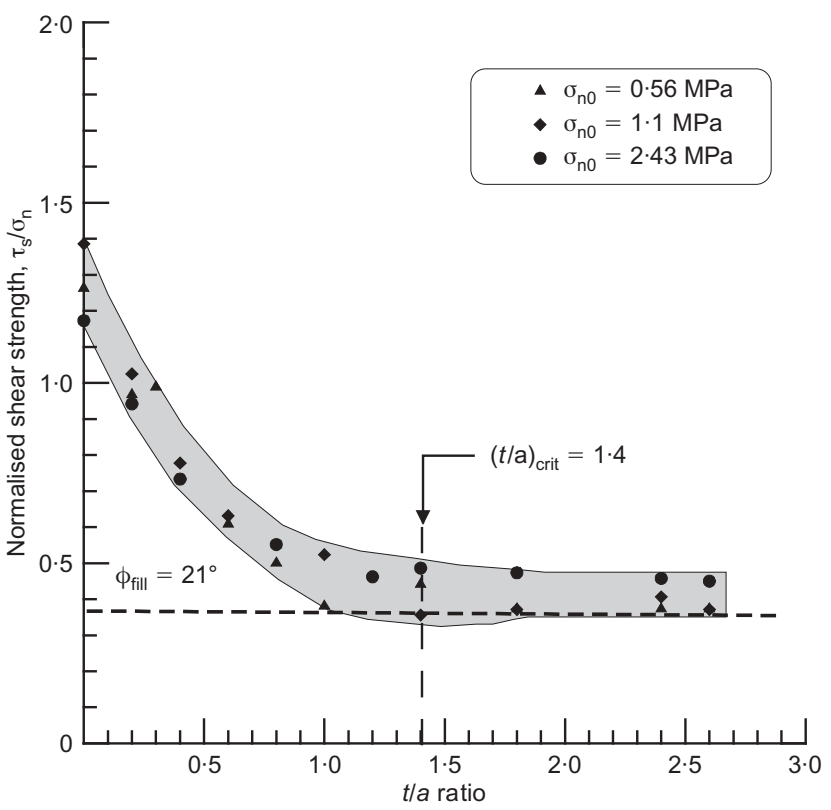

(b)

Fig. 6. Variation of normalised shear strength with $t / a$ ratio and critical $t / a$ ratio for graphite-infilled joints: (a) joint Type 1; (b) joint Type 2

a low friction, granular fill (graphite); (b) a clay fill (bentonite); and (c) a clayey sand. While the $\alpha$ values for Type 2 joints are slightly less than or almost equal to those of Type 1 joints for the same infill, the $\beta$ values are substantially higher than the Type 1 values (Table 1). For other types of infill in Type 1 or 2 joints it may be possible to obtain rough estimates of $(\alpha, \beta)$ by interpolation between the values given in Table 1. Nevertheless, for practical application, further testing is necessary to develop a more comprehensive database covering a larger array of infill-joint combinations.

In the proposed model, a fully drained condition with no pore pressure build-up in the infill, and negligible infill cohesion, has been assumed. For commercial bentonite and graphite prepared at initial moisture contents of less than $20 \%$, consolidated-drained shear tests have confirmed that the cohesion intercept of both fills is almost zero (Welideniya, 2004). 


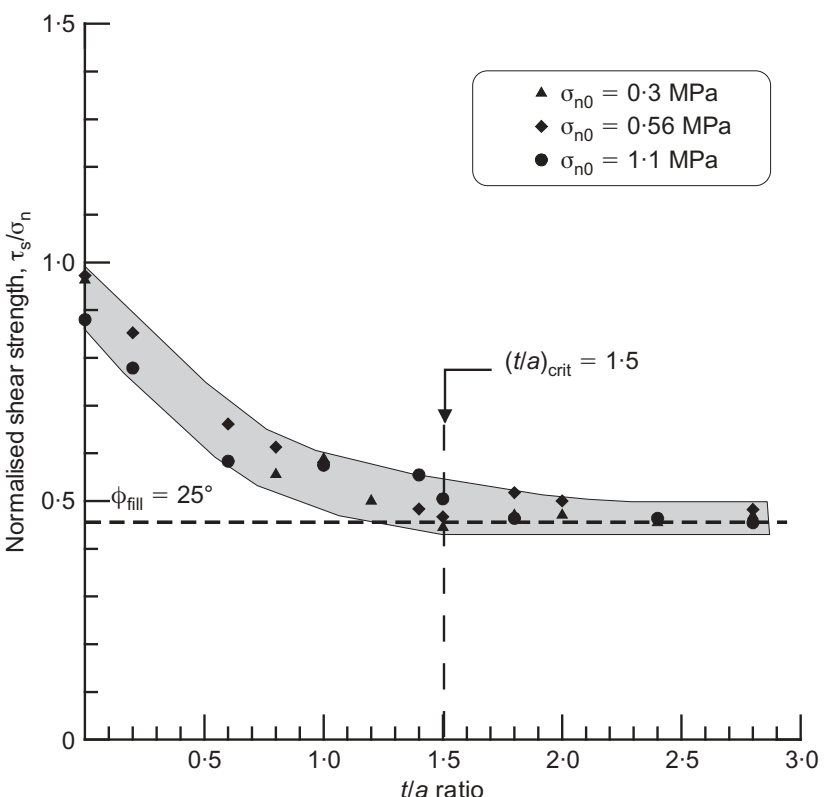

(a)

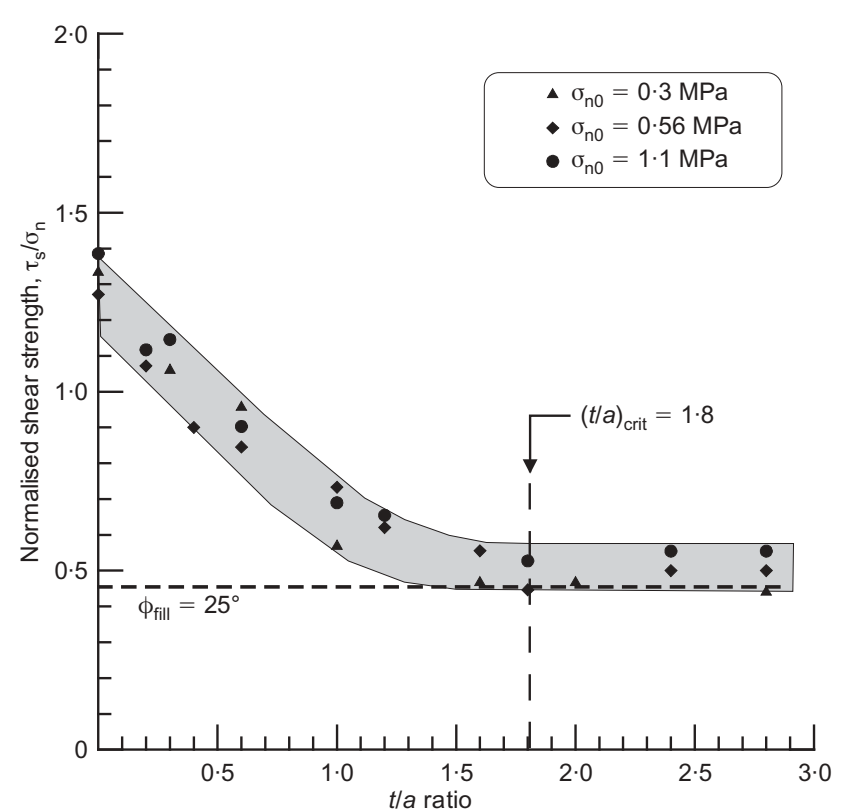

(b)

Fig. 7. Variation of normalised shear strength with $t / a$ ratio and critical $t / a$ ratio for bentonite-infilled joints: (a) joint Type 1; (b) joint Type 2

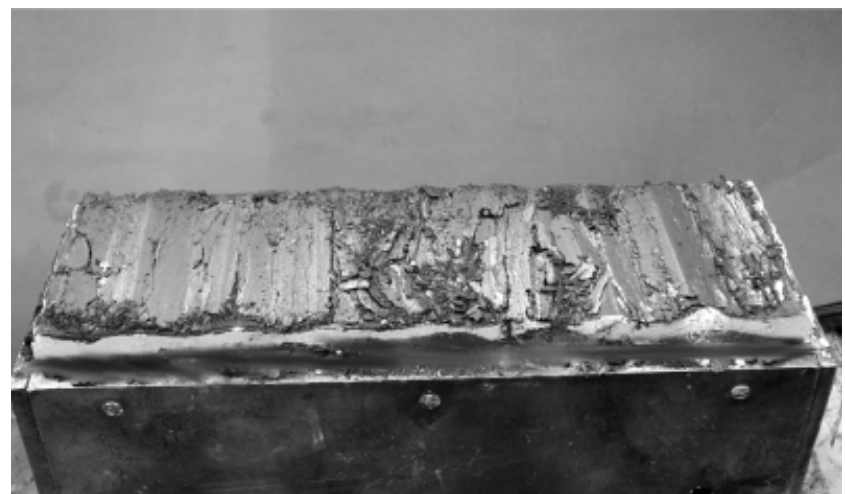

Fig. 8. Compacted and polished surface of graphite infill in some parts of the specimen after shearing

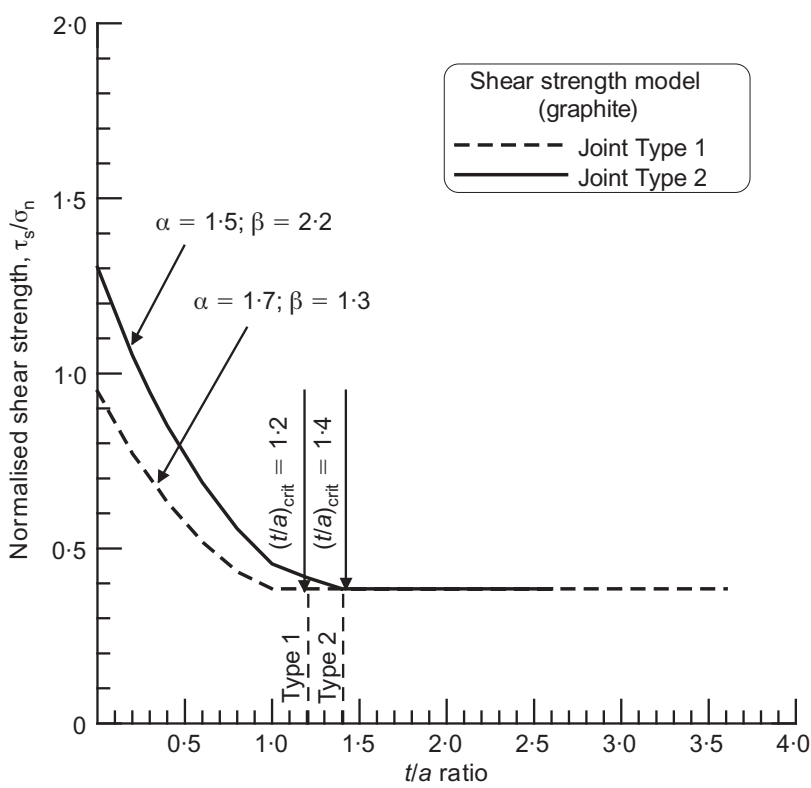

(a)

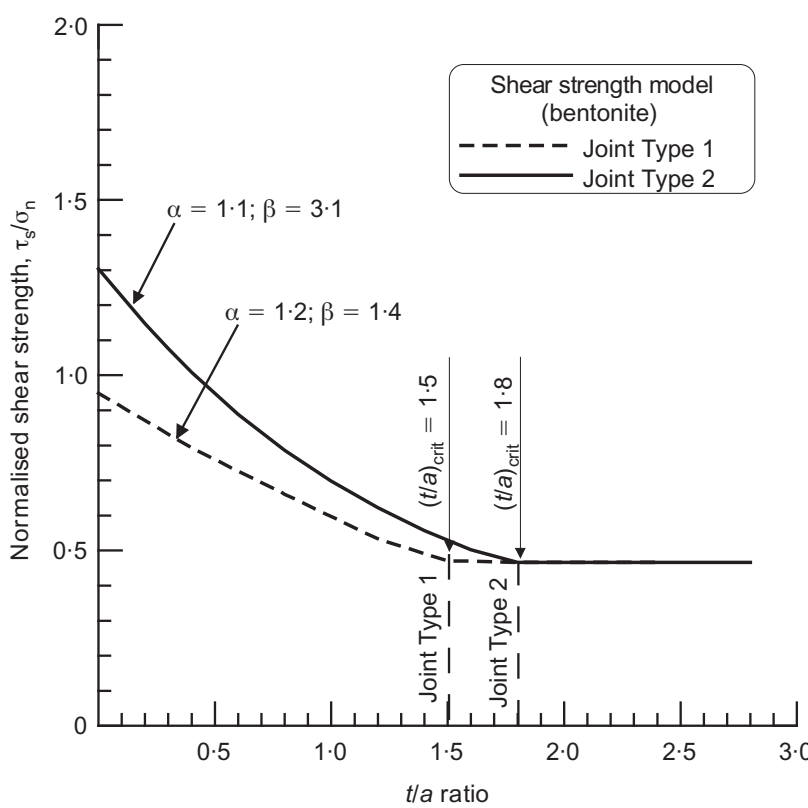

(a)

Fig. 9. Summary of joint Types 1 and 2 based on the proposed shear strength model: (a) graphite infill; (b) bentonite infill

Change in normal stress during CNS shearing

Figure 10 plots the variation in the $\sigma_{\mathrm{n}} / \sigma_{\mathrm{n} 0}$ ratio with $t / a$. The data show that the increase in $\sigma_{\mathrm{n}}$ is greater at lower $t / a$ ratios and smaller values of $\sigma_{\mathrm{n} 0}$. In the case of graphiteinfilled joints for $\sigma_{\mathrm{n} 0}=2.43 \mathrm{MPa}$, even at $t / a$ ratios less than critical, the $\sigma_{\mathrm{n}} / \sigma_{\mathrm{n} 0}$ ratio varies slightly above unity (Figs 10(a) and 10(b)). The possible reasons for this are that (a) the higher the value of $\sigma_{\mathrm{n} 0}$ the smaller the joint dilation from the start, as shearing tends to occur partly through asperities, and (b) the graphite infill itself is readily compressed and oriented (polished) in the direction of shearing (see Fig. 8), preventing the build-up of normal stress, in contrast to bentonite and clayey sand. For all joints, beyond $(t / a)_{\text {cr, }}$, where the influence of the asperities is diminished because of the thicker infill, the $\sigma_{\mathrm{n}} / \sigma_{\mathrm{n} 0}$ ratio approaches unity. 


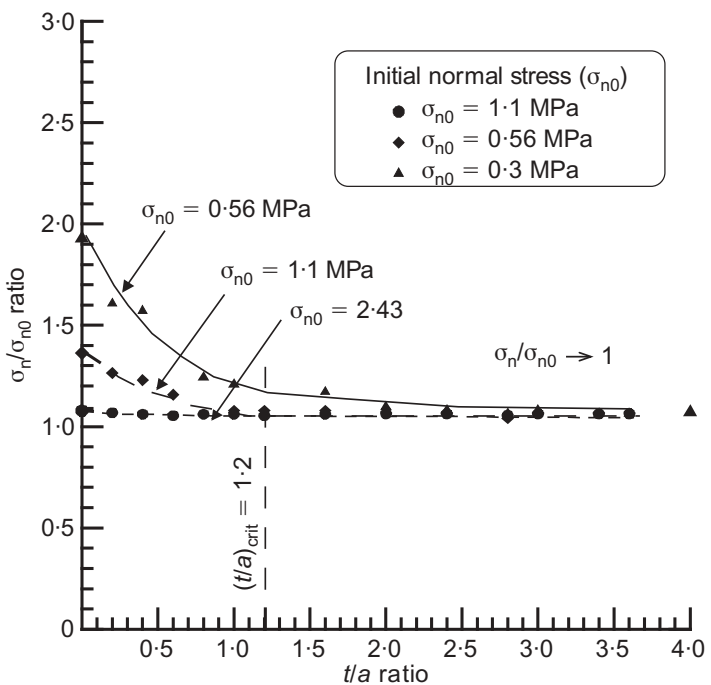

(a)

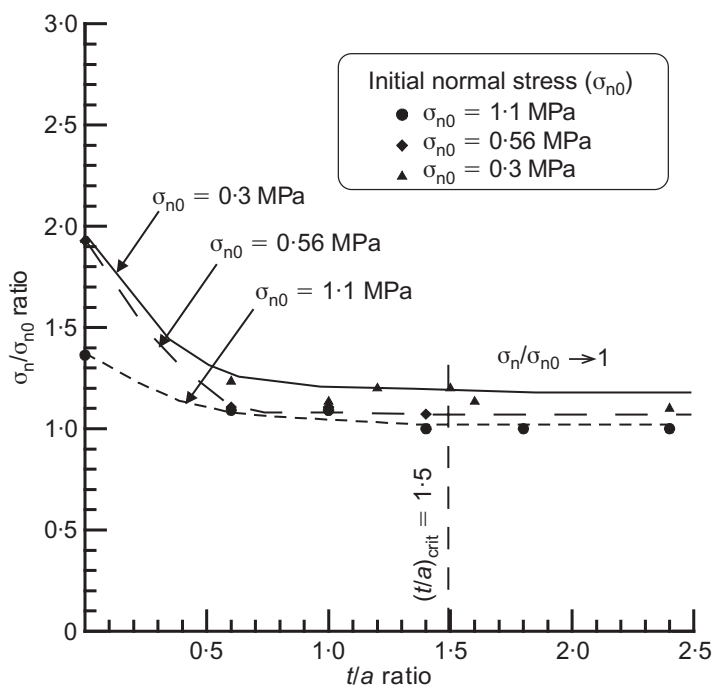

(c)

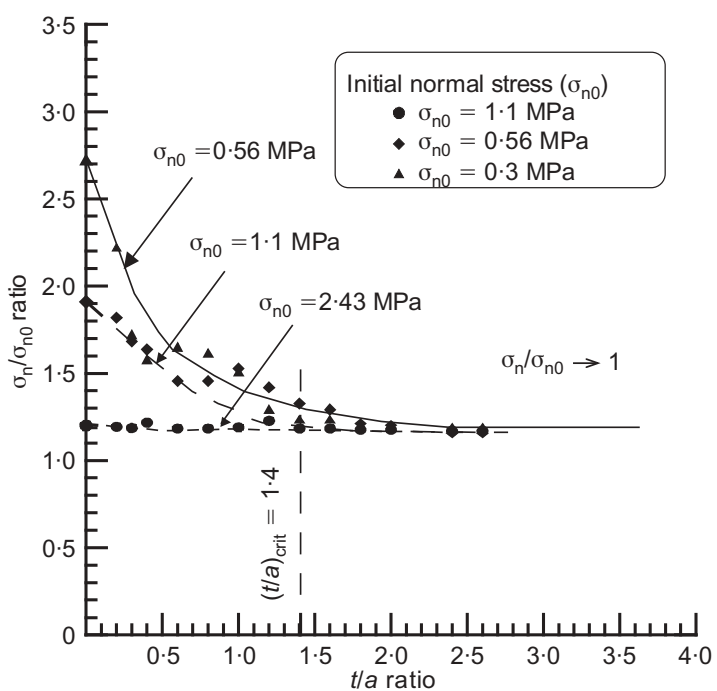

(b)

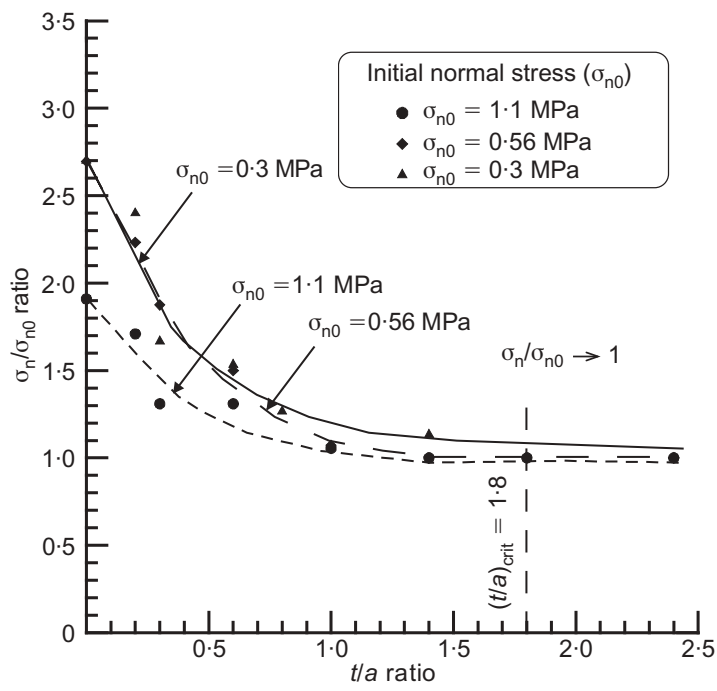

(d)

Fig. 10. Variation of $\sigma_{\mathrm{n}} / \sigma_{\mathrm{n} 0}$ with increasing $t / a$ ratio: (a), (b) Types 1 and 2 of graphite-infilled joints; (c), (d) Types 1 and 2 of bentonite-infilled joints

The variation of the $\sigma_{\mathrm{n}} / \sigma_{\mathrm{n} 0}$ ratio with increasing $t / a$ takes the form

$$
\frac{\sigma_{\mathrm{n}}}{\sigma_{\mathrm{n} 0}}=\left(\frac{2}{1+\kappa}\right)^{\gamma}
$$

where $\kappa$ is the ratio $(t / a) /(t / a)_{\mathrm{cr}}$ and $\gamma$ is an empirical parameter that depends on the initial normal stress. After $(t /$ $a)_{\text {cr }}$ is exceeded (i.e. $\kappa>1$ ), the value of $\gamma$ approaches zero. The relation given by equation (10) is of use if the initial normal stress conditions are known, so that $\sigma_{\mathrm{n}}$ can be conveniently replaced by $\sigma_{\mathrm{n} 0}$ in equations (8) and (9).

\section{PRACTICAL IMPLICATIONS}

For the types of joint profile and infill material tested under a particular stress regime and normal stiffness, the CNS strength envelope for an equivalent rock mass falls slightly below the direct shear CNL envelope for all $t / a$ ratios (Indraratna et al., 1999; Welideniya, 2004). At very low stresses a higher angle of friction is given by the CNL envelope, but as the normal stress increases a reduction in the slope of the envelope occurs, producing a bi-linear trend. At higher stresses approaching $2.5 \mathrm{MPa}$, the envelopes merge together. Consequently, in the case of an 'equivalent' rock mass, for example, weathered greywacke with graphite intrusions, shear strength parameters derived from the CNS envelope may give more realistic (smaller) factors of safety in stability analyses (e.g. in jointed rock slopes, underground excavations, rock bolts and rock socketed piles) than those arising from CNL testing. The normalised shear strength model developed enables the CNS shear strength to be determined for any $t / a$ ratio for a given infill-joint profile combination, as long as the empirical coefficients $\alpha$ and $\beta$ are evaluated by laboratory testing at a known constant normal stiffness. As the magnitude of the initial normal stress $\left(\sigma_{\mathrm{n} 0}\right)$ is determined by the state of stress existing in the given application, CNS testing needs to be conducted at the relevant stress levels. Equations (8) and (10) with an appropriate value of $\gamma$ can be used to determine the shear strength developed for a given value of $\sigma_{\mathrm{n} 0}$.

The required values of the basic friction angle of the joint $\left(\phi_{\mathrm{b}}\right)$ and the infill angle of friction $\left(\phi_{\text {fill }}\right)$ are easily determined by laboratory tests, if estimates cannot be made from 
the available literature. Using these values with an appropriate set of empirical values $(\alpha, \beta)$ such as those given in Table 1, the shear strength $\left(\tau_{\mathrm{s}}\right)$ can be estimated for an assumed t/a ratio and initial normal stress. For a given problem such as a jointed slope or a wedge sliding underground, the CNS factor of safety can then be calculated using established procedures (e.g. Priest, 1993; Brady \& Brown, 2004). In numerical analysis involving infilled joints the proposed shear strength model can be used in conjunction with modern software (e.g. the discrete element code, UDEC) through appropriate subroutines.

\section{Limitations of study}

(a) A normal stiffness constant of $8.5 \mathrm{kN} / \mathrm{mm}$ (equivalent to $0.45 \mathrm{GPa} / \mathrm{m}$ for a joint area of $190 \mathrm{~mm} \times 100 \mathrm{~mm}$ ) was used in all CNS tests. Although this value is reasonable for some highly weathered and/or soft sedimentary joints and fractured graphite mine environments, a higher value may be required for stiffer joints.

(b) The need for repeatability of tests warranted the use of idealised joint profiles (Fig. 1), which do not represent naturally undulating joints.

(c) Scale effects were not considered, as all joints had the same plan area and limited joint profiles. Effects of the change in wavelength were not studied.

(d) Three types of infill in two different joint profiles cannot represent all types of real joints and the vastly inhomogeneous nature of infills.

(e) The application of the model is limited in routine practice by the need to perform a series of CNS tests to obtain the relevant coefficients.

\section{CONCLUSIONS}

The experimental results obtained highlight the influence of the ratio of infill thickness to asperity height $(t / a)$ in reducing the shear strength from the maximum value associated with clean rough joints. For graphite- and bentoniteinfilled joints at infill thicknesses exceeding a critical t/a ratio the influence of the asperities is suppressed, and the shear behaviour is influenced mainly by the infill. In this case, there is minimal variation of normal stress and dilation with shear displacement. An increase in asperity angle from $9.5^{\circ}$ to $18.5^{\circ}$ for the same infill thickness (reducing the $t / a$ ratio) produced:

(a) increased shear stress and dilation for the same initial normal stress, $\sigma_{\mathrm{n} 0}$

(b) the more pronounced occurrence of two peaks, the first corresponding to the shear strength of the infill, and the second including the effect of asperity interference

(c) after the second peak, a sharper drop to minimum shear stress associated with the asperities sliding down to the 'fully mated' position.

The proposed shear strength model explains the decrease of shear strength with increasing $t / a$ ratio, and highlights the role of the critical $t / a$ ratio, beyond which no further reduction in shear strength occurs. The model neglects any infill cohesion in its present form. Although it has been validated for graphite-, bentonite- and clayey sand-infilled joints represented by low $k_{\mathrm{n}}$, further testing of other infilljoint geometry combinations is recommended at higher $k_{\mathrm{n}}$ values, in order to establish a more comprehensive database for use in field applications. The proposed model can be applied to rock engineering problems, once the relevant parameters $(\alpha, \beta)$ have been evaluated in the laboratory for representative infilled joints. The use of the proposed model in conjunction with numerical software codes such as UDEC will require appropriate subroutines, which are currently being developed by the authors.

\section{ACKNOWLEDGEMENTS}

The authors wish to acknowledge the contributions of Alan Grant (Technical Officer, University of Wollongong) during the laboratory testing programme. The financial sponsorship for the $\mathrm{PhD}$ research of the second author was provided through the Asian Development Bank, and the Ministry of Science \& Technology, Sri Lanka.

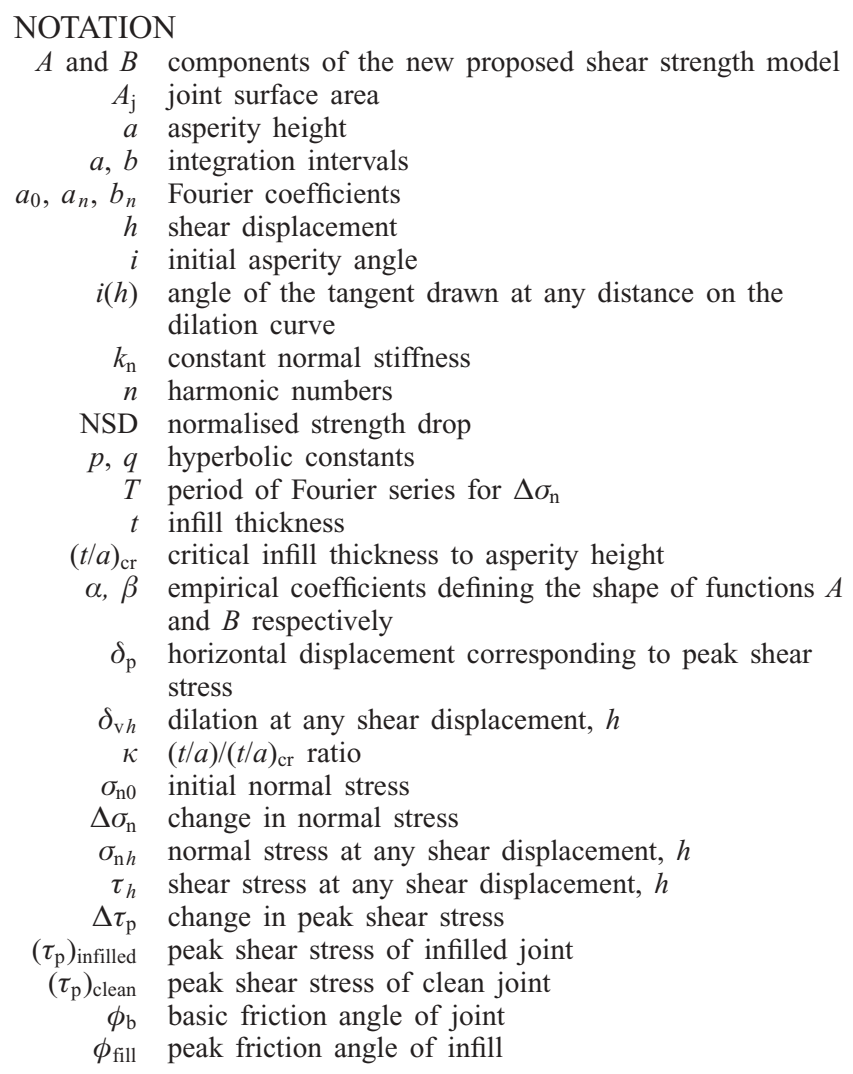

\section{REFERENCES}

Barla, G., Forlati, F. \& Zaninetti, A. (1985). Shear behaviour of filled discontinuities. Proceedings of the international symposium on fundamentals of rock joints, Bjorkliden, pp. $163-172$.

Barton, N. (1974). Review of shear strength of filled discontinuities in rock, Publication No. 105. Oslo: Norwegian Geotechnical Institute.

Barton, N. R. \& Choubey, V. (1977). The shear strength of rock joints in theory and practice. Rock Mech. 10, No. 1, 1-54.

Bertacchi, P., Zaninetti, A., Barla, G. \& Forlati, F. (1986). Laboratory tests on the shear behaviour of filled discontinuities. Proceedings of the international symposium on engineering in complex rock formation, Beijing, pp. 262-270.

Brady, B. H. G. \& Brown, E. T. (2004). Rock mechanics for underground mining, 3rd edn. Dordrecht: Kluwer Academic.

Brown, E. T. (2004). The mechanics of discontinua: engineering in discontinuous rock masses, John Jaeger Memorial Lecture. Proc. 9th Australia New Zealand Conf. on Geomechanics, Auckland 1, $51-72$.

Chappell, B. A. (1975). Friction characteristic of graphite coated bedding joints in shale. Int. J. Rock Mech. Min. Sci. Geomech Abstr. 12, No. 2, 33-39.

Czichos, H. (1978). Tribology: A systems approach to the science and technology of friction, lubrication and wear. Amsterdam: Elsevier Scientific.

de Toledo, P. E. C. \& de Freitas, M. H. (1993). Laboratory testing 
and parameters controlling the shear strength of filled rock joints. Géotechnique 43, No. 1, 1-19.

Goodman, R. E. (1976). Methods of geological engineering. St Paul: West Publishing.

Haberfield, C. M. \& Johnston, I. W. (1994). A mechanistically based model for rough rock joints. Int. J. Rock Mech. Min. Sci. Geomech. Abstr. 31, No. 4, 279-292.

Haque, A. (1999). Shear behaviour of soft rock joints under constant normal stiffness. PhD thesis, University of Wollongong, Australia.

Hoek, E. (1983). Strength of jointed rock masses. Géotechnique 33, No. $3,187-223$

Hutchings, I. M. (1992). Tribology: Friction and wear of engineering materials. London: Edward Arnold.

Indraratna, B. (1990). Development and applications of a synthetic material to simulate soft sedimentary rocks. Géotechnique $\mathbf{4 0}$, No. 2, 189-200.

Indraratna, B. \& Haque, A. (2000). Shear behaviour of rock joints. Rotterdam: Balkema.

Indraratna, B. \& Welideniya, H.S. (2003). Shear behaviour of graphite infilled joints based on constant normal stiffness test conditions. Proc. 10th Congr. Int. Soc. Rock Mech.: Technology roadmap for rock mechanics, Johannesburg 1, 569-574.

Indraratna, B., Haque, A. \& Aziz, N. (1999). Shear behaviour of idealised joints under constant normal stiffness. Géotechnique 49, No. 3, 331-355.

Jaeger, J. C. and Cook, N. G. W. (1979). Fundamentals of rock mechanics, 3rd edn. London: Chapman \& Hall.

Kanji, M. A. (1974). Unconventional laboratory tests for the determination of the shear strength of soil-rock contacts. Proc. 3rd Congr. Int. Soc. Rock Mech., Denver 2, 241-247.

Kutter, H. K. \& Rautenberg, A. (1979). The residual shear strength of filled joints in rock. Proc. 4th Congr. Int. Soc. Rock Mech., Montreux l, 221-227.

Ladanyi, B. \& Archambault, G. (1977). Shear strength and deformability of filled indented joints. Proc. 1st Int. Symp. Geotechnics of Structurally Complex Formations, Capri, 317-326.

Lama, R. D. (1978). Influence of clay fillings on shear behaviour of joints. Proc. 3rd Int. Assoc. Engng Geol., Madrid 2, 27-34.

Ludema, K. C. (1996). Friction, wear and lubrication. Boca Raton, FL: CRC Press.

Lupini, J. F., Skinner, A. E. \& Vaughan, P. R. (1981). The drained residual strength of cohesive soils. Géotechnique 17, No. 2, $181-213$.

Nieto, A. S. (1974). Experimental study of the shear stress-strain behaviour of clay seams in rock masses. $\mathrm{PhD}$ thesis, University of Illinois, USA.

Newland, P. L. \& Alley, B. H. (1957). Volume changes in drained triaxial tests on granular materials. Géotechnique 7, 17-34.

Ohnishi, Y. \& Dharmaratne, P. G. R. (1990). Shear behaviour of physical models of rock joints under constant normal stiffness conditions. Rock joints: Proceedings of the international conference on rock joints (eds N. Barton and O. Stephansson), pp. 267-273. Rotterdam: Balkema.

Papaliangas, T., Hencher, S. R., Lumsden, A. C. \& Manolopoulou, S. (1993). The effect of frictional fill thickness on the shear strength of rock discontinuities. Int. J. Rock Mech. Min. Sci. Geomech. Abstr. 30, No. 2, 81-91.

Patton, F. D. (1966). Multiple modes of shear failure in rocks. Proc. 1st Congr. Int. Soc. Rock Mech., Lisbon 1, 509-513.

Pereira, J. P. (1990). Mechanics of filled discontinuities. In Mechanics of jointed and faulted rock (ed. H. P. Rossmanith), pp. 375-380. Rotterdam: Balkema.

Phien-wej, N., Shrestha, U. B. \& Rantucci, G. (1990). Effect of infill thickness on shear behaviour of rock joints. Rock joints: Proceedings of the international conference on rock joints (eds N. R. Barton and O. Stephansson), pp. 289-294. Rotterdam: Balkema.

Priest, S. D. (1993). Discontinuity analysis for rock engineering. London: Chapman \& Hall.

Seidel, J. P. \& Haberfield, C. M. (1995). The application of energy principles to the determination of the sliding resistance of rock joints. Rock Mech. Rock Engng 28, No. 4, 211-226.

Skinas, C. A., Bandis, S. C. \& Demiris, C. A. (1990). Experimental investigations and modelling of rock joint behaviour under constant stiffness. Rock joints: Proceedings of the international conference on rock joints (eds N. R. Barton \& O. Stephansson), pp. 301-307. Rotterdam: Balkema.

Welideniya, H. S. (2004). Shear behaviour of graphite and clay infilled joints under constant normal stiffness conditions. $\mathrm{PhD}$ thesis, University of Wollongong, Australia.

Xu, S. \& de Freitas, M. H. (1988). Use of rotary shear box for testing of the shear strength of rock joints. Géotechnique 38, No. 2, 301-309. 